(c)2000 A 'erican Institute of Aeronautics \& Astronautics or published with permission of author(s) and/or author(s)' spōnsōrīng örganizatīon.'

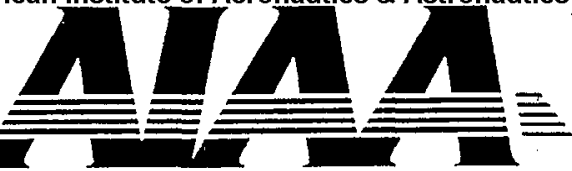

A00-16865

\title{
AIAA-2000-1053 \\ Status of US Testing of the High Performance Hall System SPT-140 Hall Thruster
}

W. Hargus Jr., J. Fife, K. McFall

US Air Force Research Laboratory

Edwards AFB, CA

R. Jankovsky, L. Mason

NASA Glenn Research Center

Cleveland, $\mathrm{OH}$

J. Snyder, S. Malone

Space Systems Loral

Palo Alto, CA

J. Haas, A. Gallimore

University of Michigan

Ann Arbor, MI

N. Bauer

Sverdrup Technology, Inc.

Edwards A.FB, CA

\section{8th Aerospace Sciences Meeting \& Exhibit 10-13 January 2000 / Reno, NV}




\title{
Status of US Testing of the High Performance Hall System SPT-140 Hall Thruster
}

\author{
W. Hargus Jr., J. Fife, K. McFall \\ US Air Force Research Laboratory \\ Edwards AFB, CA \\ R. Jankovsky, L. Mason \\ NASA Glenn Research Center \\ Cleveland, $\mathrm{OH}$ \\ J. Snyder, S. Malone \\ Space Systems/Loral \\ Palo Alto, CA \\ J. Haas, A. Gallimore \\ University of Michigan \\ Ann Arbor, MI \\ N. Bauer \\ Sverdrup Technology, Inc. \\ Edwards $A F B, C A$
}

\begin{abstract}
The High Performance Hall System (HPHS) program supports the development and Hight qualification of a $+.5 \mathrm{~kW}$ electric propulsion system that includes the SPT-140 Hall thruster. The Air Force Research Laboratory (AFRL) and International Space Technology', Inc. (ISTI) are co-funding the HPHS program which is being conducted by a team led by Atlantic Research Corporation (ARC). The team includes ISTI, Experimental Design Bureau Fakel (Fakel), and Space SystemsiLoral (S/SL). The Research Institute of Applied Mechanics and Electrodynamics (RIAME) also provided support for this project. The SPT-140 is being designed, developed, manufactured, and tested by Fakel in Kaliningrad, Russia, where extensive performance testing and advanced development have been performed. In addition to the testing in Russia, a suite of experiments on the development model and the qualification model thrusters, sponsored by the US Gorernment, has occurred during 1999 and is scheduled to occur in 2000. These experiments include thruster performance, plume characterization, electromagnetic compatibility, and life characterization. This paper presents the status of government testing of the SPT-140 in the Lnited States.
\end{abstract}

\section{Introduction}

Due to their high specific impulse and thrust efficiencies, Hall thrusters are now being considered for use on commercial, research, and mulitary spacecraft. This technology provides economic advantages for a number of missions and its use can be translated into lower launch mass, longer time on station, or larger payloads. The US Air Force, NASA, and industry have shown interest in high power $(-5 \mathrm{~kW})$ Hall thruster systems as spacecraft have grown both in size and electrical power capacity. The High Performance Iall Systcm (HPHS) program is developing a $4.5 \mathrm{~kW}$ Hall propulsion system that provides significant payoffs for

This work is a declared work of the LIS Government and is not subject to copyright protection in the Lnited States. station-keeping, repositioning, and orbit raising applications.

\section{Program Description}

The Air Force Research Laboratory (AFRL) and Intermational Space Technology, Inc. (ISTI) are co-funding this cost shared contract (56\% government, $44 \%$ contractor) under the auspices of the Integrated High Payoff Rocket Propulsion (II-PRPT) initiative. Atlantic Research Corporation (ARC) is the prime contractor. The propulsion system includes the thruster, power processing unit (PPU), propellant management assembly (PMLA), and simulated spacecraft hardware. The Experimental Design Bureau/Takel, a Russian 
designer and manufacturer of over 110 tlight Hall thrusters, is developing the thruster. Space Systems/ Loral (S/SL), leveraging their flight qualification experience with the $1.35 \mathrm{~kW}$ SPT-100 Hall system, is designing and manufacturing the PPU. An existing, Moog Inc. built, flight qualified PMA completes the major system components.

The primary objective of the HPHS program is to meet US Air Force IHPRPT goals of improved performance for orbit transfer, apogee insertion, repositioning, and station-keeping. The development effort is focused on the improvement of thrister and PPU performance characteristics. The thruster preliminary design review (PDR) and critical design review (CDR) were successfully completed in December 1997 and March 1999, respectively. A 1200 hour extended duration test of the flight-like demonstration model (DM) thruster is underway at Fakel. The PPI PDR and CDR have also been successfully completed in November of 1998 and October of 1999, respectively. To ensure US government access to SPT-170 thruster technology, ARC will deliver a thruster design package, including engineering drawings, processes, and procedures to a US based escrow agent.

The SPT-140 thruster consists of a coaxial Hall accelerator with an outer diameter of the acceleration channel annulus of $140 \mathrm{~mm}$. All thrusters to be used in the HPHS program will be constructed by Fakel in Kaliningrad, Russia. The SPT-140 has been described in detail elsewhere [1-2]. A photograph of the SPT-140 is shown in Fig. 1.

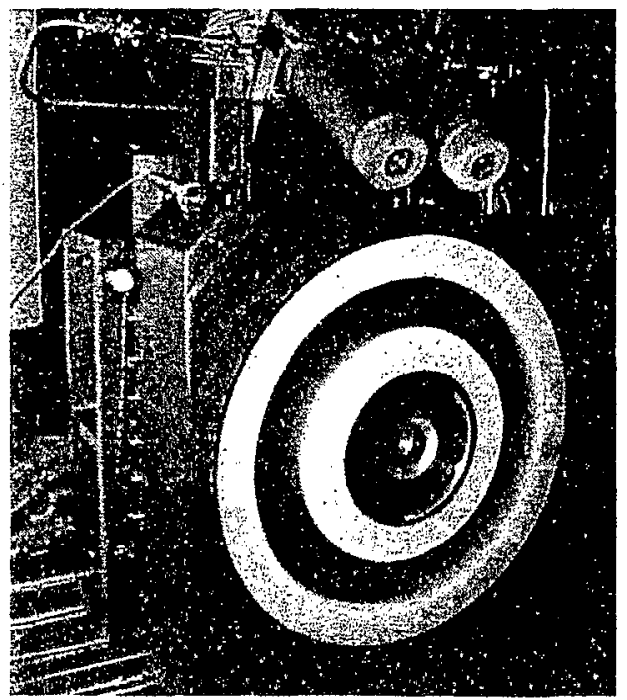

Fig. 1. Photograph of SPT-140 Hall Thruster.
In order to ensure that the SPT-140 HPHS wiil meet US Air Force requirements, an extensive series of tests is being conducted by the US Air Force in conjunction with other research and development groups. As part of the HPHS contract, ARC provided the test plans for these tests. The test plans, written by ISTI and SS/L, are based on previous US SPT-100 qualification experience.

The first test series was conducted at NASA Glenn Research Center (GRC) during August 1999. The first test consisted of a performance measurements of the SPT- 140 Hall thruster. The second test consisted of electro-magnetic interference (EMI) testing of the SPT-140. The third test consisted of plume contamination testing whose goal was to quantify the impact of the SPT-140 plume on spacecraft solar array and thermal control surfaces. These tests were co-funded by the US Air Force and NASA.

The second series of tests was conducted at the Lniversity of Michigan Plasma and Electric Propulsion Laboratory (PEPL). These tests concentrated on measurement of the plume characteristics of the SPT-1+0. The first test consisted of ion Hux measurements with guarded Faraday probes. The second series of tests measured ion energy distributions in the plume. Also during the final portion of this test program, the SS/L constructed brassboard PPU was first integrated with the SPT-140 Hall thruster.

Fabrication of the flight qualification model (QMD) thruster is expected to conclude in January of 2000. The QM thruster and brassboard PPU will undergo an integrated life test scheduled to begin in March of 2000 . The final series of tests will be a long duration integrated life test with a total thruster operation of 7,200 hours which will be performed at the AFRL Electric Propulsion Laboratory located at Edwards Air Force Base, California.

\section{Completed Tests}

Although a number of the tests described in this section have been completed, the majority of the data has not yet been analyzed. The following is a summary of the tests that have been performed or remain. Later papers will describe in more detail the results of these tests. 


\section{Testing at NASA Glenn Research Center}

The series of tests performed at GRC were completed during August 1999. All tests were performed in Chamber 6 consisting of a $7.5 \mathrm{~m}$ diameter, $18 \mathrm{~m}$ long stainless steel vacuum chamber pumped by $12 \mathrm{LN}_{2}$ cooled CVI TM-1200 reentrant cryopumps with a total pumping speed of approximately $500,0001 / \mathrm{s}$ on xenon and a base pressure of $10^{-6}$ Torr as measured on an iouization gauge calibrated for $\mathrm{N}_{2}$.

The first tests consisted of performance measurements of the DM thruster as measured on an inverted pendulum thrust stand. A preliminary analysis of these measurements indicates that the thinster performance exceeds that measured with an engineering model SPT-140 at NASA GRC [2]. Performance testing was also done at a number of pumping speeds and background pressures which was accomplished by selectively shutting down cryopumps. A total of four background pressures/ pumping speeds were examined. Performance measurements at higher background pressures indicated that some entrainment of background neutral xenon was occurring. The additional performance testing at a variety of background pressures will allow for an extrapolation of the actual performance at zero background pressure. Figure 2 shows the SPT-140 mounted on the thrust stand at GRC.

During performance testing, ion current density measurements were performed at a distance of $1 \mathrm{~m}$ from the exit plane [3]. These measurements were also performed for a variety of pumping speeds/background pressures and characterize the plume profile and how it varies with background pressure.

The second series of tests performed at GRC examined EMI produced by the SPI-140 Hall thruster. Measurements of the ENII produced by the SPI-140 were performed over five frequency regimes: $10 \mathrm{kHz}-32 \mathrm{MHz}$, passive rod; $32 \mathrm{MHz}$ $200 \mathrm{NIHz}$, biconical antenna; $200 \mathrm{MHz}-350 \mathrm{MIHz}$, broadband dipole; $350 \mathrm{MHz}-1 \mathrm{GHz}, \log$ period dipole; and $1 \mathrm{GHz}-18 \mathrm{GHz}$, double ridge guide horn. All measurements were made at a power of $3.0 \mathrm{~kW}(300 \mathrm{~V}, 10 \mathrm{~A})$.

The final set of measurements performed at GRC consisted of plume contamination testing of the Ilall thruster operating at $3.0 \mathrm{~kW}(300 \mathrm{~V}, 10 \mathrm{~A})$ and a background pressure of $1.8 \times 10^{-5}$ Torr for a period of 100 hours. A GRC test plan, derived from
SPT-140 test requirements and prior SPT-100 testing was used [4]. The test consisted of 26 samples and several controls to determine the extent and distribution of contaminant deposition. A majority of the samples consisted of solar array cover glass, but other solar array materials and thermal control samples were also included. The samples were placed on a stainless steel ring with a $2.0 \mathrm{~m}$ diameter and housed in line-of-sight tantalum collimators similar to those used in previous testing of the SPT-100 at GRC [4].

The mass, transmittance, reflectance, and emittance of the cover glass samples before and after plume exposure, along with the control sample will be examined. The other samples will also be examined. Profilometry and chemical analyses of the samples will provide additional intormation, as will depth profiling. Combined, these data will provide insight on the sequence of events that occur leading to contaminant deposition. Finally, the impact of contaminant on component performances will be evaluated.

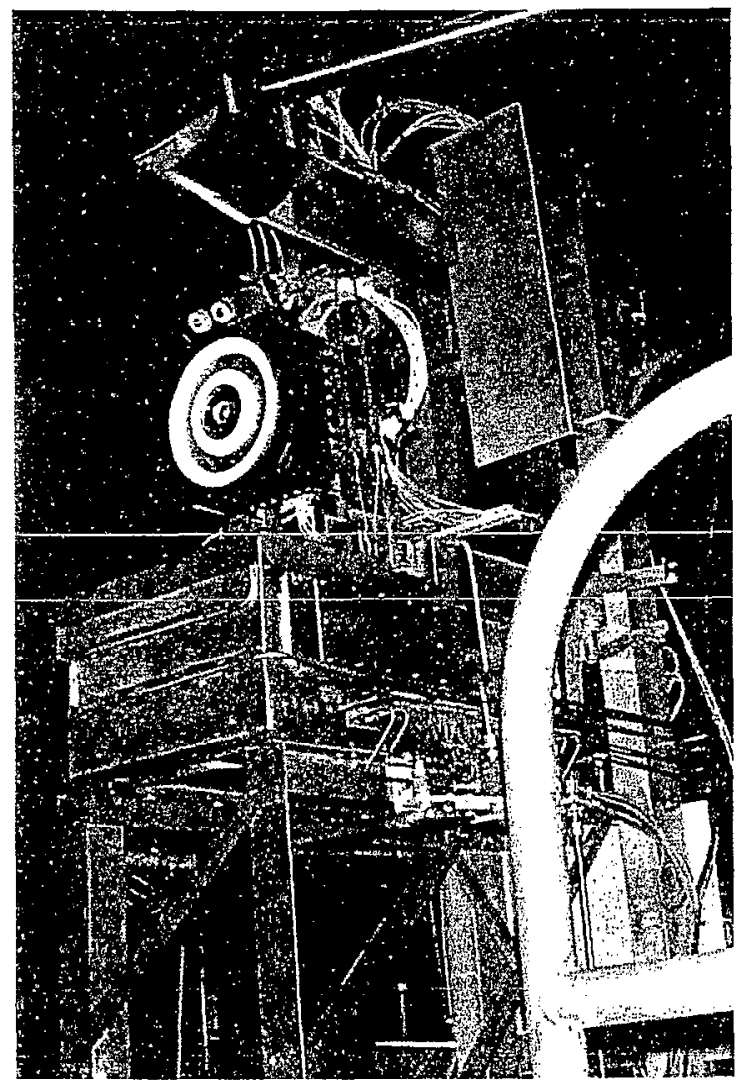

Fig. 2. Photograph of SPT-140 mounted on thrust stand at NASA GRC. 


\section{Testing at the University of Michigan}

The series of tests performed at the University of Michigan were completed during September of 1999. All tests were performed in the PEPL Large Vacuum Test Facility (LVTF) consisting of a $6 \mathrm{~m}$ diameter, $9 \mathrm{~m}$ long stainless steel vacuum chamber pumped by four $\mathrm{LN}_{2}$ cooled CVI TM-1200 reentrant cryopumps with a total pumping speed of approximately $140,000 \mathrm{l} / \mathrm{s}$ on xenon and a base pressure of $10^{-6}$ Torr as measured on an ionization gauge calibrated for $\mathrm{N}_{2}$ [5]. All tests were performed for three operating conditions consisting of $2.0 \mathrm{~kW}, 3.0 \mathrm{~kW}$, and $4.5 \mathrm{~kW}(300 \mathrm{~V})$.

The first series of tests consisted of guarded Faraday probe profiles of the ion current density at radial locations $0.5 \mathrm{~m}$ and $1.0 \mathrm{~m}$ from the exit plane. Measurements extended $\pm 100^{\circ}$ from the thrust vector and were performed in $1^{\circ}$ increments in six geometric planes, each inclined from one another by $30^{\circ}$. These planes correspond to roll angles of the SPI-140 and were taken by mounting the thruster on a rotation stage which allowed the thruster to rotate in the azimuthal direction. Both sets of measurements were taken simultaneously by placing the probes on one radial arm with an angular offset of $20^{\circ}$. No evidence of interaction of the $0.5 \mathrm{~m}$ probe with the $1.0 \mathrm{~m}$ probe was seen. Preliminary results indicate that the two profiles are symmetric about thrust axis and do not appear to be affected by the cathode location. The experimental mounting of the SPT-140 is shown in Fig. 3.

The second series of tests consisted of Electro-Static Analyzer (ESA) measurements of ion

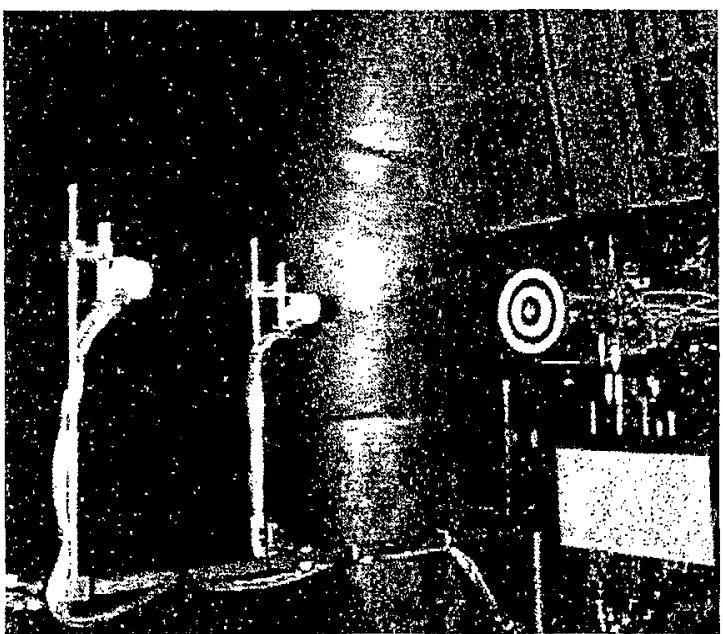

Fig. 3. Experimental setup for current density measurements at the University of Michigan. energy distributions. The ESA is a miniature version of the Molecular Beam Mass Spectrometer (NBMMS) previously used to characterize the plume of the SPI-100 [6,7]. Unlike the MBMS, the ESA does not have time-of-flight mass spectrometry capability; however, it uses the same principle to measure ion energy distributions with a resolution of approximately $2 \%$.

For tcsts measuring the ion energy distribution, the SPT-140 was placed on a rotation stage allowing motion in the yaw direction. The rotation stage and thruster were in turn mounted on a linear translation stage with a $1+m$ range of motion. With the ESA fixed, the ion energy distribution for thruster angles of $\pm 100^{\circ}$ and radial distances of 0.5 $\mathrm{m}$ and $1.0 \mathrm{~m}$ were taken for the $3 \mathrm{~kW}$ and $4.5 \mathrm{~kW}$ operating conditions. Ion energy distributions for the $2 \mathrm{~kW}$ operating condition were taken at $0.5 \mathrm{~m}$ at thruster angles between $0^{\circ}$ and $100^{\circ}$

-The final milestone achieved during the University of Michigan portion of the HPHS test program was the testing of the SS/L PPU [8]. The brassboard PPU was shipped to the University of Michigan for initial integration tests with the SPT140. The PPU was successfully used to power the SPT-140 throughout its range of operating conditions.

\section{Life Test of HPHS}

A 7,200 hour life test of the HPHS, including the SPT-1+0 and S/SL brassboard PPU, is scheduled to begin in March 2000. The life test will have a duration of approximately 12 months. The firing profile will attempt to simulate the SPT-140 HPHS performing a combination of orbit raising followed by a series of station-keeping and repositioning events.

The life test will be performed in an AFRL high vacuum facility currently being constructed at Edwards Air Force Base, California specifically for this test. The facility consists of a large cylindrical vacuum chamber $3 \mathrm{~m}$ in diameter and $10 \mathrm{~m}$ in length. The roughing system consists of a dedicated dry Stokes mechanical pump and blower arrangement with a total pumping speed of $450 \mathrm{l} / \mathrm{s}$. Upon initial evacuation of the vacuum facility to approximately 20 mTorr, a turbo molecular pump with a nominal pumping speed of $1,000 \mathrm{l} / \mathrm{s}$ is activated to lower the chamber pressure to the cross-over pressure for the cryogenic pumping system. The cryogenic pumping system consists of four $0.6 \mathrm{~m}$ by 2.0 
$\mathrm{m}$ and four 0.6 by $2.5 \mathrm{~m}$ helium panels cooled to approximately $20 \mathrm{~K}$. These panels are in turn shrouded by a system of Polycold( $(\mathbb{B})$ baffles to insulate the helium refrigerated panels from heat sources such as the ambient chamber walls and the Hall thruster plume. The total pumping speed of the facility is estimated to be approximately $350,0001 / \mathrm{s}$ on xenon and provide a background pressure better than $2 \times 10^{-5}$ Torr during operation of the SPT- 140 . Construction is on schedule and the chamber will be completed by January 2000 .

The vacuum system will be instrumented to monitor the environment in which the test will be carried out. Two redundant ionization gauges and two cold cathode gauges will be used to monitor the background pressure during the test. All pressure measurements will be traceable to National Institute of Standards and Technology (NIST) standards. Pressure measurements will be supplemented with two residual gas analyzers which will monitor the relative proportions of background gases in the vacuum facility.

The life test of the HPHS will be extensively instrumented. The primary mission of the life test diagnostics package will be to monitor the performance of the SPT-140. This will be accomplished with an inverted pendulum thrust stand previously used in tests at AFRL [9]. The thrust stand has full scale of $360 \mathrm{mN}$ and an accuracy better than $\pm 3 \mathrm{mN}$.

In addition to the primary mission of performance measurement, the life test diagnostics will also measure a variety of other thruster characteristics. In order to provide an indication of how the plume divergence changes over the lifetime of the thruster, a probe rake with seven guarded Faraday probes similar to those previously used at GRC and PEPL will be placed approximately 1 in from the thruster exit plane. The probes will characterize the ion current density of the plume with sweeps occurring periodically during testing. To measure and record the erosion of the SPT- 140 insulator, a comparative photographic system will be utilized. A charge coupled device (CCD), 1064 by 1064 elements with a resolution better than $200 \mu \mathrm{m}$, will capture images of the thruster front face through a shuttered view port. The port is approximately $3 \mathrm{~m}$ from the thruster exit plane and angled at $45^{\circ}$ from the vacuum facility centerline. The images of the thruster will be correlated to produce a time history of the erosion of the SPI- 140 insulator throughout

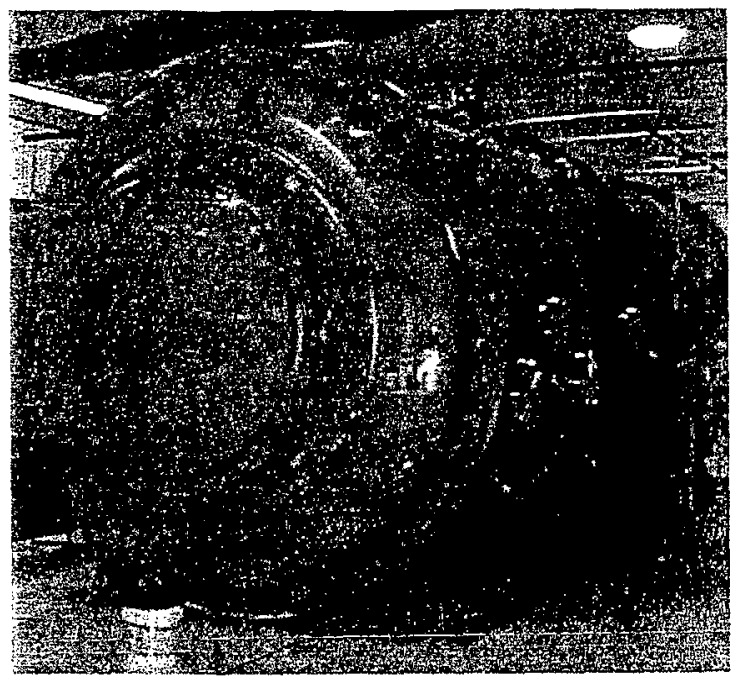

Fig. 4. New AFRL vacuum facility for HPHS life extended duration life testing.

the life test. A photograph of the vacuum facility is shown in Fig. + .

Due to the long duration of the testing at AFRL, the vast majority of the diagnostics will be automated. Thruster operations will be monitored and recorded using an Hewlett-Packard HP34970A data logger that will allow the setting of trip points which will be used to ensure the test remains within the specified parameters. The entire thrust measurement procedure will be automated, including the measurements and periodic calibration of the thrust stand. The Faraday probe measurements of the plume will also be automated such that no operator interaction is required to complete the diagnostic program. The erosion measurements will also be automated in a similar manner. The diagnostics system control will consist of a PC running the National Instruments LabView (B) software package which will provide the logic to operate the diagnostics. The diagnostic computer will ultimately control the test by interacting with the computer controlling the PPU.

An exciting techuology transition opportunity has arisen concerning the HPHS SPT-140 Hall thruster. MILSATCOM has approved an extended duration orbit transfer (90 days) for the Advanced EHF satellite slated to replace the current MILSTAR system starting in 2006. The Advanced EHF program is a defined near term priority for the Air Force Space Command [10]. The HPHS would provide both north-south station-keeping and orbit transfer operations. Currently, the SPT-140 is being evaluated at the Aerospace Corporation for this mis- 
sion. The HPHS will have a technical maturity sufficient to transition to commercial users based on ground test data gathered in this program.

\section{Conclusions}

A substantial portion of the US tests to qualify the HPHS have been completed. These include performance, EMI, and plume contamination testing performed at GRC as well as plume and ion energy profiling performed at the University of Michigan. The data from these tests have not yet been fully analyzed and this paper contains only initial results and test status. Forthcoming papers will describe the results of these tests in more detail.

Preparations are continuing for the HPHS life test to be perfonned at AFRL. Technology transition opportunities for the HPHS are driving these tests so that this technology may be trausferred to commercial users. The new vacuum facility will be completed in January 2000. It is anticipated that check-out of the vacuum facility will proceed as schcduled and the life test will begin by March of 2000. The life test will then be completed by April 2001.

\section{Acknowledgments}

The authors would like to thank the many engineers, mechanics, and other support personnel at GRC, the University of Michigan, SS/L, and AFRL who have labbored so diligently to ensure the continuing success of the SPT-140 HPHS qualitication project.

\section{References}

1. D. Manzella, J. Hamley, J. Miller, C. Clauss, K, Kozusky, and R. Gnizdor, "Operation Characteristics of the SPT-140 Hall Thruster," AIAA-97-2919, 33rd Joint Propulsion Conference, July 1997, Seattle, WA.

2. D. Manzella, C. Sarmiento, J. Sankovic, and T. Haag, "Performance Evaluation of the SPT-140," IEPC-97-059, 25th International Electric Propulsion Conference, Aug. 1997, Cleveland, OH.

3. D. Manzella, J. Sankovic, "Hall Thruster Ion Beam Characterization," AIAA-95-2927, 31st Joint Propulsion Conference, July 10-12, 1995, San Diego, CA.

4. E. Pencil, T. Randolph, and D. Manzella, "End-of-Life Stationary Plasma Far Field Plume Characterization," AIAA-96-2709, 32nd Joint Propulsion Conference, July 1-3, 1996, Lake Buena Vista, FL.

5. G. Williams Jr., T. Smith, F. Gulczinski III, B. Beal, A. Gallimore, R. Drake, "Laser Induced Fluorescence Measurement of Ion Velocities in the Plume of a Hall Effect Thruster," AIAA-99-2424, 35th Joint Propulsion Conference, June 20-23, 1999, Los Angeles, CA.

6. J. Pollard, "Plume Angular, Energy, and Mass Spectral Measurements with T5 Ion Engine,"AIAA-95-2920, 31st Joint Propulsion Conference, July 10-12, 1995, San Diego, CA:

7. L. King, "Transport-Property and Mass Spectral Measurements in the Plasma Exhaust Plume of a Hall-Effect Space Propulsion System," Ph.D. Dissertation, University of Michigan, 1998.

8. D. Pidgeon, G. Fischer, J. Waranauskas, P. Clayton, D. Jasek, and B. Suppanz, "4.5 kW Hall Thnuster Power Processor Development," 1909-01-1381, SAE Acrospace Power Systems Conference, Apr. 1999, Mesa, AZ.

9. K.A. McFall, D.L. Tilley, and F.S. Gulczinski III, "Low Power Arcjet Performance Evaluation," IEPC-95-18, 24th International Electric Propulsion Conference, Sept. 1923, 1995, Moscow, Russia.

10. 1998 Strategic Master Plan, CD-Rom, Department of the Air Force, Air Force Space Command, 1998. 